\title{
Clientelismo e participação nas políticas públicas de desenvolvimento rural no Brasil
}

\author{
Clientelism and participation in public policies for rural development in \\ Brazil
}

Eric Sabourin ${ }^{1,2}$ (1)

${ }^{1}$ Centre de Coopération Internationale en Recherche Agronomique pour le Développement (CIRAD), Umr Art-Dev, Muse Montpellier, France. E-mail: eric.sabourin@cirad.fr

${ }^{2}$ Centro do Desenvolvimento Sustentável (CDS), Programa Meio Ambiente e Desenvolvimento Rural (MADER), Universidade de Brasília (UnB), Brasilia (DF), Brasil.

Como citar: Sabourin, E. (2020). Clientelismo e participação nas políticas públicas de desenvolvimento rural no Brasil. Revista de Economia e Sociologia Rural, 58(4), e217798. https://doi.org/10.1590/1806-9479.2020.217798

\begin{abstract}
Resumo: O artigo trata da permanência de práticas clientelistas e das suas tensões com o enfoque participativo adotado no marco da política pública brasileira de desenvolvimento territorial rural, em particular no caso da implementação local do Programa Nacional de Desenvolvimento Territorial. Os resultados provêm do estudo do funcionamento do Colegiado Territorial e dos projetos implementados no Território Águas Emendadas no centro-oeste do Brasil. Recorre a um enfoque socioantropológico do clientelismo e da participação política mediante a análise da configuração social e das relações de instrumentalização tanto nos espaços participativos como nos projetos desse território. Os resultados mostram a existência de uma dimensão, não somente social, mas afetiva da prática de clientela que pode ser analisada como uma relação de reciprocidade assimétrica a partir do princípio da reciprocidade antropológica ou como um processo de intercâmbio político desigual, se for a partir da ciência política.
\end{abstract}

Palavras-chave: relações de clientela, reciprocidade, políticas públicas, participação política, Brasil.

\begin{abstract}
The study discusses the permanence of clientelistic practices and their tensions with the participatory approach adopted within the framework of the Brazilian public policy of rural territorial development. It examines, in particular, the case of local implementation of the National Program of Territorial Development. The results come from the study of the Territorial Collegiate functioning and the projects implemented in the Águas Emendadas Territory in the Brazilian Midwest. It was used a socio-anthropological approach of patronage and political participation through the analysis of the social configuration and the relations of instrumentalization as much in as in the participatory spaces and the projects of this territory. The results show the existence of a not only social but also an affective dimension of clientele practice that can be analyzed as an asymmetrical reciprocity relationship based on the principle of anthropological reciprocity or as a process of unequal political exchange, considering political science approach.
\end{abstract}

Keywords: patronage relationship, reciprocity, public policies; political participation, Brazil.

\section{Introdução}

O objetivo deste artigo é examinar a permanência ou a reconfiguração de práticas clientelistas (Carvalho, 2003; Avelino Filho, 1994) na implementação recente de políticas de desenvolvimento rural no Brasil (Freitas, 2016).

A noção de clientelismo "[...] indica um tipo de relação entre atores políticos que envolve concessão de benefícios públicos, na forma de empregos, vantagens fiscais, isenções, em troca de apoio político, sobretudo na forma de voto" (Carvalho, 1997, p. 134). 
Por meio de sucessivos projetos de pesquisa e pesquisa-ação, tenho tido a oportunidade de verificar tais práticas, onde menos as esperava, no marco da política territorial do Ministério de Desenvolvimento Agrário (MDA) e da Casa Civil, precisamente por se tratar de programas fundados na participação dos beneficiários na implementação e na avaliação das ações.

Esclareço que de modo algum considero que a implementação dessa política pública tenha sido caracterizada por práticas clientelistas. Pelo contrário, os montantes reduzidos dos orçamentos alocados aos diversos territórios rurais do país associados à participação e controle social da definição e implementação das ações territoriais pelos beneficiários têm provavelmente contribuído para reduzir o clientelismo com relação a práticas e políticas anteriores. Mas, precisamente, nesse contexto político renovado, o objeto específico da minha análise foi examinar a permanência ou a reconfiguração de novas formas ou expressões clientelistas associadas à abordagem participativa, ou bem entrando em tensão com ela.

O estudo de caso que fundamenta este trabalho corresponde à implementação do Programa Nacional de Desenvolvimento Territorial (PRONAT) entre os anos 2005 e 2015 no Território Águas Emendadas (TAE) que reúne o Distrito Federal (DF) e sete municípios da sua periferia dos Estados de Goiás e Minas Gerais no centro-oeste do Brasil. O PRONAT existiu desde 2004 e foi prolongado a partir de 2008 pelo Programa Territórios da Cidadania (PTC) que funcionou até 2016, coordenado pela Casa Civil, mas executado pela Secretaria de Desenvolvimento Territorial (SDT) do MDA. Os dois programas, caracterizados por concepções e práticas inovadoras, em particular a implementação de uma escala territorial intermunicipal e a dimensão participativa, foram extintos a partir de outubro de 2016, depois do impeachment da Presidente Dilma Roussef e da transformação do MDA em Secretaria de Agricultura Familiar e Desenvolvimento (SEAD) ${ }^{1}$.

A metodologia tem mobilizado uma análise sociológica e antropológica do funcionamento do Colegiado e das Comissões do Território Águas Emendadas (COTAE) e de projetos elaborados no seio desse espaço de concertação (Landel, 2009; Sabourin, 2009; Ávila et al., 2011; Lecuyer, 2009). A abordagem empírica associou o estudo da configuração social dos atores (Elias, 1994), dos grupos de interesse (Grossman \& Saurugger, 2006) e dos projetos formulados pelo COTAE, cruzando observação participante nas reuniões, análise de arquivos e entrevistas entre 2005 e 2015 no marco de três projetos ${ }^{2}$.

A abordagem sociológica examinou a recomposição das relações sociais, dos jogos de poder, das alianças e de cooptação entre atores, no marco dos novos espaços de coordenação ou de discussão que constituem a plenária e as comissões do colegiado territorial. O enfoque antropológico considerou a estruturação dessas relações na concepção e implementação dos projetos territoriais, na distribuição dos recursos do programa, mas também na atribuição e negociação dos postos de conselheiros ou de representantes nas comissões técnicas do COTAE. A partir desse enfoque antropológico, o artigo propõe, na prolongação de Marcel Mauss (1931) considerar a importância das relações estruturantes de reciprocidade entre os atores da política e analisar o clientelismo como uma forma de reciprocidade assimétrica (Medard, 1976).

O artigo conta com três partes. A primeira apresenta o contexto sociopolítico brasileiro no período do estudo, o referencial científico e a metodologia do estudo. A segunda parte examina a configuração social e as relações clientelistas na implementação local do PRONAT no Território Águas Emendadas. A terceira parte completa e discute os resultados pela leitura da dimensão afetiva da relação de clientela de acordo com o princípio da reciprocidade antropológica.

\footnotetext{
1 Desde o ano 2019, no marco da administração do governo Jair Bolsonaro, a SEAD foi extinta e parte das suas funções está sendo assumida por uma Secretaria da agricultura familiar integrada ao Ministério da Agricultura, Pecuária e Abastecimento (MAPA); a política territorial rural foi abandonada.

2 Projeto "Contribuição dos dispositivos coletivos dos agricultores, a renovação dos instrumentos de políticas públicas de desenvolvimento rural" (CNPq, UnB-SOL, Cirad, 2005-2009); Projeto "Renovação da Ação Pública Territorializada de desenvolvimento rural", RAPT (Cirad, UnB-CDS, Capes - 2009-2014) Projeto "Território, Pobreza e Políticas Públicas: uma abordagem pela territorialização" (Capes-Cofecub, CPDA-UFRRJ, Cirad-Art-Dev, UFSC-CAA, UnB-CDS, 2014-2016).
} 


\section{Contexto institucional e referencial teórico e metodológico}

\section{Um Brasil ainda clientelista}

O Brasil é um país de tradição clientelista (Avelino Filho, 1994; Faoro, 2001). Os trabalhos pioneiros de Nunes Leal (1948) analisam o sistema político brasileiro do Século XIX, fundado no poder de milícias dirigidas pelos grandes proprietários de terra chamados de "coronéis". Esses impunham o voto aos camponeses e trabalhadores rurais sobre os quais tinham autoridade e dever de proteção, geralmente garantida ou encoberta pelo poder político central. O Presidente Campos Sales (1898-1902) cria assim a "política dos governadores", fortalecendo as relações sociopolíticas a partir de uma cadeia de favores indo do presidente até as populações rurais, passando pelos governadores dos Estados Federados e, obviamente, pelos coronéis, patrões da política local (Farias, 2000). Para explicar esse caráter patrimonial do sistema político brasileiro, fundado em relações de poder individualistas, personalizadas e muito desiguais, Raimundo Faoro (2001) tem mobilizado a história colonial e a herança do escravismo, destacando a permanência tardia dos coronéis ou dos seus descendentes na política moderna dos Estados do Nordeste. Lanna (1995) analisa especificamente as relações de favores recíprocos entre políticos locais herdeiros dos coronéis e a população rural do Rio Grande do Norte e defende uma teoria da dádiva sacralizada em termos de "dívida divina".

Sempre no Nordeste, Bursztyn (2008) estudou as relações de clientelismo no marco da arrumação do território nos anos 1970-80, em torno dos grandes projetos de desenvolvimento integrado e do acesso ao crédito rural. No posfácio da terceira edição em 2008, trinta anos mais tarde, constata a manutenção desses tipos de relações, mas através de novos mediadores: os vereadores, extensionistas agrícolas, mas também as Organizações Não Governamentais (ONGs) têm substituído os coronéis. Fiz a mesma observação em diversos projetos e programas de agricultura irrigada nos Estados da Bahia e Pernambuco, onde os serviços técnicos e as ONGs disputam o poder de mediação e de tutela com os políticos regionais e a Igreja Católica (Sabourin et al., 1997). José de Souza Martins (1994) incluía a Igreja Católica entre essas tutelas; hoje devemos agregar as igrejas evangelistas (Centro Estratégico Latino-Americano de Geopolítica, 2017). Martins, um dos maiores sociólogos rurais do Brasil, define no livro "O poder do atraso" (1994) o clientelismo como "uma relação de troca de favores políticos por benefícios econômicos". Para Martins, trata-se, essencialmente, de "uma relação entre os poderosos e os ricos e não principalmente entre os políticos e os eleitores". Pois, segundo ele, muito antes de os pobres votarem, o Estado já estabelecia com os ricos uma relação de troca de favores. É nesse cenário que se fortalece a "cultura da dádiva" (Lanna, 1995) e se negocia ou reduz o acesso a direitos sociais e direitos politicos constitucionais adquiridos, mediante favores (Martins, 1994).

A política clientelista ligada ao voto veio substituir antigos laços de lealdade pela oferta de benefícios materiais. Essa intermediação dá-se pela moeda política que é o favor, o que implica uma condição de débito a ser cobrado (Avelino Filho, 1994; Farias, 2000).

Segundo Dagnino (1994), a cultura política do clientelismo está implantada na sociedade brasileira em diversas esferas da vida social: família, Estado, trabalho, instituições escolares, assistência social, cultura. Nessa tradição, as relações sociais estariam fundamentadas, principalmente, no clientelismo, apadrinhamento, desigualdade e violência (Dagnino, 1994).

Yazbek (1993, p. 50) chama de "matriz do favor" a cultura do assistencialismo no desenvolvimento social que deveria entrar em tensão ou em contradição com grupos e movimentos sociais ativos, que reivindicam o exercício pleno de sua cidadania (Dagnino, 1994). Era o que se esperava da abordagem participativa das políticas públicas, reivindicada pelos movimentos sociais do campo (Sabourin, 2015).

\section{Novas políticas participativas}

Desde os anos 1990, o Brasil se tornou um verdadeiro laboratório de ação pública participativa (Avritzer, 2008, 2009). Para Pellegrini Filho \& Rovere (2011, p. 01), 
[...] a participação social e política tem um valor intrínseco, como um dever e um direito das populações de participar de decisões que lhes afetem, e, ao mesmo tempo, um valor instrumental, garantindo o apoio político necessário para viabilizar a redistribuição de poder e recursos que permita o combate às iniquidades.

Segundo Jesus Junior \& Costa Cosenza $(2015$, p. 1), “[...] a participação social na gestão pública deve ser utilizada como um meio de influenciar e contribuir na construção das políticas públicas locais, através da relação entre os diversos atores sociais e o Estado". Esses autores lembram que o princípio da participação popular na gestão pública ganhou destaque no parágrafo único do artigo $1^{\circ}$ da Constituição Federal de 1988, o qual afirma que "[...] todo poder emana do povo, que o exerce por meio de representantes eleitos, ou diretamente [...]" (Brasil, 1988, 2008, p. 1). Essa participação popular direta passou a ser vista como uma forma de aproximação entre a sociedade e o Estado, levando em consideração a diversidade de interesses e, principalmente, o surgimento de espaços para o debate desses interesses coletivos, principalmente de tipo do comité gestor, do conselho setorial ou territorial ou do fórum (Avritzer, 2008; Gohn, 2011).

Em realidade, progressivamente, ao lado da participação cidadã através das eleições, dos referendos ou dos plebiscitos, chamada de democracia representativa (as pessoas elegem os integrantes do Poder Executivo e do Poder Legislativo), tem se desenvolvido a participação da população ou da sociedade civil organizada na formulação ou até implementação de programas, projetos e até de instrumentos de políticas públicas em espaços de discussão e negociação. Essa segunda forma de participação social e cidadã é chamada também de democracia técnica (Callon et al., 2001). De fato, os representantes eleitos ou designados nos conselhos gestores participam de uma competência, experiência ou prática técnica num determinado setor de atividade.

A descentralização tem levado à criação de conselhos municipais setoriais (saúde, educação, desenvolvimento rural, segurança alimentar, Agenda 21). Os conselhos foram associados a processos de participação dos beneficiários nas decisões ou na definição de ações prioritárias, seja no caso dos orçamentos participativos (Porto de Oliveira, 2017) seja, mais recentemente, naquele da territorialização do desenvolvimento rural (Oliveira, 2011; Freitas, 2016; Leite \& Wesz Junior, 2012; Wanderley, 2014; Perafan et al., 2018).

No setor rural, a dupla dimensão da territorialização e da participação começou a se firmar a partir de 1996, com a criação dos Conselhos Municipais de Desenvolvimento Rural Sustentável (CMDRS) no bojo da criação do Programa Nacional de Fortalecimento da Agricultura Familiar - PRONAF (Grisa et al., 2014). Um segmento do programa não contemplava crédito individual, mas a atribuição de subsídios para o financiamento de infraestruturas coletivas municipais, decididas após um processo de diagnóstico no seio dos CMDRS (Leite \& Wesz Junior, 2012). A partir de 2003, o processo foi ampliado através do PRONAT com a atribuição de fundos do Programa Nacional de Infraestrutura (PROINF) para ações intermunicipais, discutidas e decididas no seio dos Colegiados Territoriais que reuniam representantes das organizações da agricultura familiar e do setor público (Oliveira, 2011; Freitas, 2016). Quaisquer que sejam os sucessos e as limitações da multiplicação dos conselhos e fóruns em matéria de ação pública territorial, diversos autores constatam a manutenção de relações clientelistas nesse novo marco participativo (Goirand, 1998; Sayago, 2000; Wanderley, 2014).

Para Dagnino \& Tatagiba (2010, p. 179), essa persistência se opõe às expectativas criadas no momento da implantação das instâncias participativas: “Esperava-se que a criação desses espaços para o encaminhamento dos pedidos apresentados como direitos de debate e negociação, permitisse pôr fim aos mecanismos tradicionais de relações preferenciais."

Essa constatação pode parecer paradoxal, na medida em que a instauração de enfoques participativos não pode pretender eliminar vários séculos de cultura política; porque as desigualdades sociais e políticas persistem, mesmo se a pobreza foi reduzida no período de 2003 a 2012 (Instituto de Pesquisa e Economia Aplicada, 2012). É o caso em matéria de acesso à informação, à saúde, à educação e, obviamente, às capacidades de decisão. Uma das interpretações do clientelismo atual, inclusive entre os movimentos sociais, é aquela de demandas públicas encaminhas mediante encontros privados, "[...] quer dizer fora dos canais 
participativos no seio dos quais esses mesmos movimentos atuam [...]" (Dagnino \& Tatagiba, 2010, p. 182) ou nos espaços paralelos (Massardier, 2008).

Dagnino \& Tatagiba (2010, p. 185) propõem considerar

[...] a coexistência de matrizes culturais distintas que colocam lado a lado o discurso dos direitos e a mobilização das redes pessoais, a insistência sobre a autonomia e a prática do clientelismo. Os princípios da participação, da cidadania e da democracia coexistem com o recurso a relações personalizadas e clientelistas, como maneira de acessar o Estado, numa situação definida como tensão constitutiva. No entanto, não se trata de uma situação de oposição, mas de uma combinação contraditória e ambivalente que persiste e orienta ainda a ação dos movimentos.

\section{Um quadro de análise: o clientelismo como relação de reciprocidade}

No mesmo sentido da coexistência das matrizes culturais de Dagnino e Tatagiba, propomos aprofundar a proposta de Jean François Medard (1976, p. 107-108) que define o clientelismo como "uma relação de reciprocidade ou de troca recíproca". Ele nota que essa reciprocidade, mesmo se mutuamente benéfica às duas partes, é ambígua, porque desigual. Mas, conclui Medard (1976, p. 109),

[...] a relação de dependência na relação de clientela é em realidade fundada sobre a reciprocidade" o que implica a expectativa de um retorno do serviço ou do favor pela adesão política ou o voto, mas também pela reprodução do laço entre as duas partes. É a conjunção entre bilateralidade e desigualdade que fixa a relação de clientela, "mas nessa base podem se edificar estruturas mais complexas (Medard, 1976, p. 114).

Segundo a teoria da reciprocidade em antropologia (Scubla, 1985; Temple, 1998, 2003), a relação de clientela corresponde à uma estrutura de reciprocidade centralizada e geralmente desigual, comparável a certas formas de redistribuição no sentido de Polanyi (1944). Trata-se, assim, de uma relação assimétrica de serviços e favores mútuos gerando laço social e, pelo tanto, irredutíveis em termos de troca mercantil (Sabourin, 2009). A diferença entre a relação de troca desigual e a relação de reciprocidade (mesmo assimétrica) reside no laço social produzido e nos valores humanos que lhe são associados como tenho mostrado no caso do Brasil rural (Sabourin, 2009, 2011). Assim, a relação de clientela se diferencia do clientelismo, porque a relação instrumental é associada a uma relação afetiva que redobra a produção de laço social.

O clientelismo político no Nordeste do Brasil reproduz a herança do paternalismo rural. O sistema de "morada" dos moradores de fazenda (Garcia Junior, 1990), relação de reciprocidade bilateral e assimétrica, funciona ainda por conta da dependência, mas também do respeito dos valores humanos ligados às relações de reciprocidade.

A fidelidade dos camponeses, cujo voto obrigatório era chamado de "cativo" (Garcia Junior, 1990), inclusive em períodos recentes, num contexto talvez menos violento, tem a ver com o respeito da palavra dada. "Sou tão pobre que só tenho a minha palavra", me confiou uma camponesa de Massaroca (Juazeiro - Bahia), "[...] a família Silva me ajudou, e vou votar para o seu candidato, não posso negar o último bem que é meu, a minha palavra".

O retorno da democracia em 1984, num contexto de analfabetismo, de voto obrigatório e de dependência socioeconômica, tem remobilizado práticas clientelistas do aparelho político brasileiro (Bursztyn, 2008).

\section{Métodos}

A metodologia mobilizou um quadro analítico socioantropológico. A abordagem sociológica, examinou a recomposição das relações sociais, dos jogos de poder, das alianças e das cooptações entre os conselheiros, representantes dos agricultores familiares e do setor público, tanto na escala dos CMDRS como do COTAE, seja nas reuniões plenárias ou naquelas das comissões do colegiado territorial. 
O enfoque antropológico examinou a estruturação dessas relações na concepção e implementação dos projetos territoriais, na distribuição dos recursos do programa, mas também na atribuição e negociação dos postos de conselheiros ou de representantes nas comissões técnicas do COTAE. Finalmente, analisou-se o papel e as evoluções das relações estruturantes de reciprocidade entre os atores da política. De acordo com a classificação de Temple (1998), existem cinco relações estruturantes elementares. A reciprocidade binária apresenta dois subtipos: i) a relação de "cara a cara" corresponde a práticas de cooperação, aliança, ajuda mútua entre dois indivíduos, duas famílias, dois grupos ou duas organizações e gera valores de respeito e de amizade; ii) o compartilhamento de recursos, segundo subtipo, produz o desenvolvimento da confiança no seio dos membros de um grupo; iii) a reciprocidade ternária (envolvendo no mínimo três partes) pode ser unilateral (entre gerações) ou bilateral (reversível entre vários sujeitos) e produz valores de responsabilidade entre os sujeitos; iv) a reciprocidade ternária generalizada (relações simétricas entre todos) produz valores de justiça e de igualdade, hoje se manifesta principalmente nas festas; v) finalmente, a reciprocidade centralizada existe quando um centro de poder e de redistribuição tem a possibilidade de captar contribuições de sujeitos sobre os quais exerce um poder de dominação ao mesmo tempo que uma responsabilidade de distribuição. Corresponde à figura do coronel, do dono da fazenda, do patrão local. Essa relação assimétrica gera prestígio do centro de poder e submissão dos sujeitos. Pode corresponder a muitos casos de relações de clientela no Brasil rural, de acordo com as definições de Souza Martins (1994) ou de Medard (1976).

A coleta de dados associou três técnicas: observação participativa de numerosas reuniões de CMDRS dos municípios de Unaí e Cabeceiras (Minas Gerais), dos conselhos de três regiões administrativas do DF (Brazlândia, Planaltina e São Sebastião) e do Colegiado do Território Águas Emendadas entre 2005 e 2013; entrevistas de lideranças do COTAE, agricultores beneficiários do Pronaf e gestores do Pronaf e do PTC de 2008 a 2014 e análise dos documentos dos projetos do COTAE.

\section{Relações instrumentais de clientelismo no Território Águas Emendadas}

\section{O caso da ação pública territorial do PRONAT}

A passagem do financiamento de infraestruturas coletivas em nível municipal (mediante o PRONAF) para a escala territorial intermunicipal (mediante o PRONAT a partir de 2004) era uma reivindicação dos movimentos sociais do campo (Schneider et al., 2003; Sabourin, 2015).

De fato, muitas vezes, os prefeitos que presidiam os CMDRS, aproveitaram-se do seu poder para cooptar representantes das organizações de agricultores familiares da sua escolha e, assim, captar novos recursos federais ao mesmo tempo que privilegiavam a sua clientela. Como essas práticas foram criticadas pelos movimentos sociais, a política de desenvolvimento territorial rural criada pelo governo Lula da Silva, em 2003, procurou reintroduzir equidade e democracia a favor da agricultura familiar, superando ao mesmo tempo os limites do financiamento de projetos na escala municipal (Oliveira, 2011; Freitas, 2016; Perafan et al., 2018). O princípio do PRONAT foi de planejar e implementar projetos coletivos na escala de vários municípios pela concertação entre sociedade civil organizada e poderes públicos no marco dos colegiados de Desenvolvimento Territorial, os CODETER (Brasil, 2005).

O objetivo era promover dinâmicas intermunicipais, economia de escala, mas, também, contornar os poderes das oligarquias locais ou dos executivos municipais dominados por partidos políticos tradicionais.

Neste marco, em 2004, em torno de cem territórios prioritários foram identificados e homologados pela SDT que Ihes propunha um apoio metodológico para a elaboração de diagnósticos e de Planos de Desenvolvimento Territorial. O PRONAT introduziu, assim, um novo nível de gestão territorial entre o Estado Federado e o município, criando conjuntos de 10 a 20 municípios, como no caso do Território Águas Emendadas (Figura 1) em torno de Brasília. 


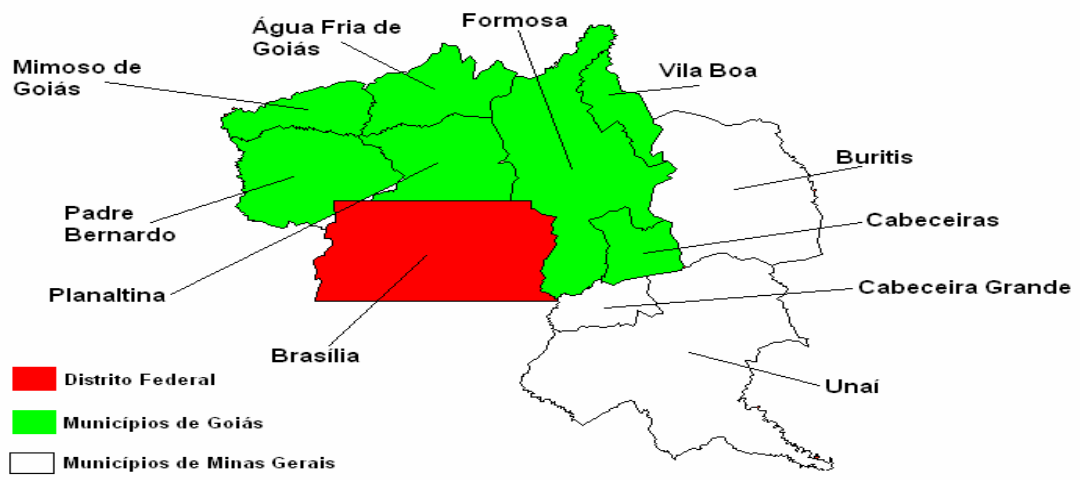

Figura 1: Mapa do Território Águas Emendadas. Fonte: Atlas dos territórios (Brasil, 2005).

O MDA procurava um reequilíbrio territorial e político em favor de zonas rurais marginalizadas com uma forte densidade de agricultores familiares. Para dar coerência "[...] aos projetos dos territórios como aos territórios de projeto [...]" (Brasil, 2005, p. 13), tratava-se de construir territórios de desenvolvimento em torno de uma identidade geográfica, cultural ou produtiva (produto típico). Mas, algumas vezes, como no caso de Águas Emendadas, foi uma lógica política clientelista em torno dos interesses do Distrito Federal (DF) que desenhou os contornos de um território onde o componente rural não deixa de ser limitado ou até artificial, pois o TAE é constituído pela bacia de aprovisionamento do DF, sendo essencialmente urbano ou periurbano por incluir a capital federal, Brasília. Esse território tem também a particularidade de reunir municípios de várias unidades federativas: o DF, o Estado de Goiás (GO) e aquele de Minas Gerais (MG).

A gestão territorial é colegial e participativa (Figure 2), mas o CODETER é essencialmente consultivo. Esse novo nível de governança, sem estatuto jurídico e sem burocracia própria, permanece frágil. Mesmo se os agricultores familiares tiveram inicialmente uma maioria de representantes, Ihes foi, geralmente, difícil implementar os projetos que tinham formulado.

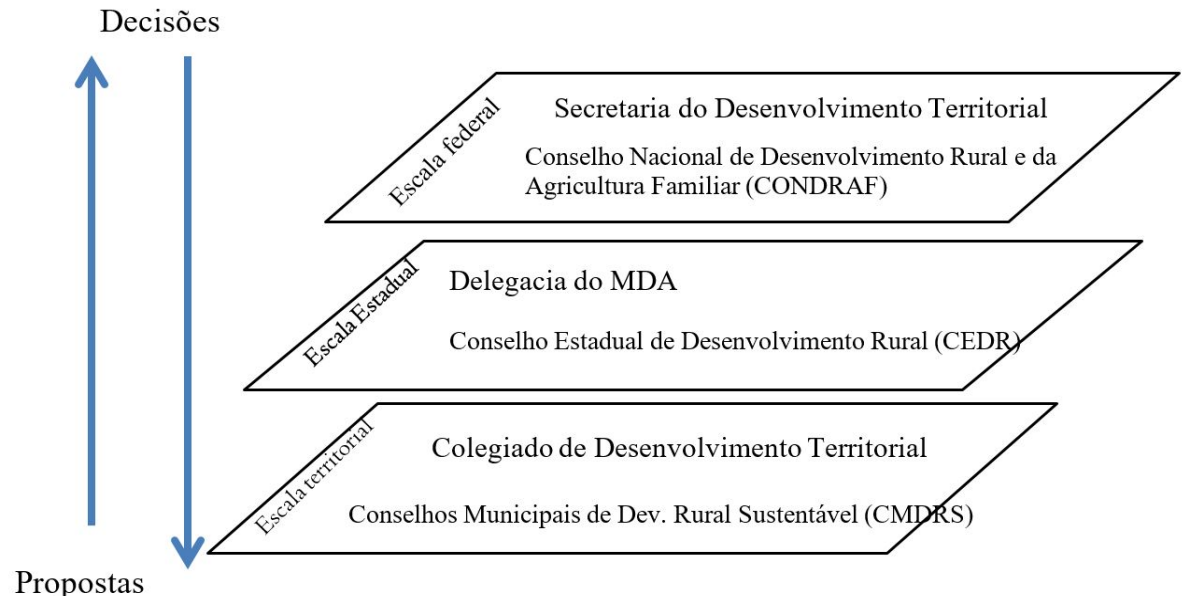

Figura 2: A gestão do PRONAT (Fonte: Sabourin et al., 2011).

O caso do Território Águas Emendadas ilustra as dificuldades do COTAE a elaborar projetos de qualidade e de dimensão territorial; mas, sobretudo, revela a sua dependência dos serviços técnicos e administrativos dos outros níveis de governo: municipal, estadual e federal (Figura 2). 


\section{Funcionamento do colegiado do Território Águas Emendadas}

A composição do CODETER reúne diferentes colégios (sociedade civil, agricultores familiares, políticos ou executivos locais e serviços técnicos). Inicialmente foi favorável aos agricultores familiares e às organizações da sociedade civil. A partir de 2008, uma diretiva da Presidência da República impôs uma paridade entre representantes dos governos (setor público) e da sociedade civil, eliminando a possibilidade de se estabelecer uma maioria a favor dos movimentos sociais do campo.

Por isso, o COTAE ilustra bem os efeitos da conjunção entre herança de rotinas clientelistas e a abordagem participativa (Briquet, 1998).

O primeiro aspecto problemático concerne à inclusão ou exclusão de certos setores da população alvo do programa, os agricultores familiares, representados pelas suas organizações. O poder de seleção dos projetos não está mais na mão dos prefeitos e executivos municipais, como no caso dos CMDRS e do ex-PRONAF "Infraestrutura Municipal". Essa seleção é orquestrada pelos serviços do governo federal (MDA) ou do Estado Federado, com a cumplicidade passiva ou ativa dos movimentos sociais. No COTAE, foi o caso dos setores minoritários do segmento da agricultura familiar (povos tradicionais, quilombolas e sem-terra) que não ofereciam interesse eleitoral (e/ou não dispunham de intermediários/mediadores políticos ou administrativos) e dos beneficiários da reforma agrária ligados ao Movimento dos Trabalhadores Sem Terra (MST) ${ }^{3}$. Enquanto o Plano de Desenvolvimento Territorial de Águas Emendadas indicava como prioridade a regularização fundiária e, em particular, aquela das áreas comunitárias, isso significava a exclusão de um amplo segmento da população alvo do programa.

O segundo mecanismo observado no seio do COTAE é aquele da permanência de antigas relações clientelistas entre os agentes dos serviços de Assistência Técnica e Extensão Rural (ATER), em particular as Empresas de Assistência Técnica e Extensão Rural - EMATER e os representantes dos agricultores familiares. Os três agricultores coordenadores do COTAE na sua criação eram pluriativos assalariados da Secretaria de Agricultura do DF, da Agência Rural de Goiás e da Prefeitura Municipal de Unaí-Minas Gerais. Esse estatuto Ihes dava a vantagem de poder assistir mais facilmente às numerosas reuniões e negociações, mas, de fato, não tinham autonomia dos seus empregadores que formatavam a sua posição (Ávila, 2011).

A terceira modalidade é a instrumentalização do dispositivo colegial de participação por uma tutela, no caso do TAE, aquela das EMATER. Na primeira assembleia do COTAE, constatou-se uma representação importante das EMATER em todos os subcolegiados: serviço federal mediante seus agentes destacados no MDA; serviço estadual mediante as Secretarias de Agricultura, tutelas das EMATER, escala municipal mediante os escritórios locais das EMATER, sociedade civil através dos seus representantes nos CMDRS e, incluso, de uma cadeira atribuída ao título da Associação de Servidores das EMATER-DF. Essa omnipresença se traduziu rapidamente pela formulação e aprovação de projetos que beneficiavam mais diretamente as suas instituições que os agricultores familiares (geralmente computadores e veículos para os serviços de ATER).

O quarto mecanismo observado é aquele da conjunção entre clientelismo e participação militante. A SDT do MDA era uma estrutura nova num ministério recém-criado sem funcionários concursados; teve que contratar muitos consultores em prazos curtos. Realizado sem seleção ou concurso nos primeiros anos, esse processo deixou livre a expressão de formas de clientelismo e de nepotismo comuns no Brasil, dessa vez militante, porque marcado pela adesão ideológica à corrente do Partido dos Trabalhadores (PT) que dominava dentro da gestão do MDA.

Outra prática destinada a superar a falta de funcionários foi o financiamento direto pela SDT, de ONGs parceiras para assegurar um apoio aos CODETER em matéria de capacitação dos conselheiros, de estudos técnicos ou para assalariar um articulador territorial terceirizado. Na criação do COTAE, o articulador era o técnico de uma ONG local ligada à

\footnotetext{
${ }^{3}$ A partir de 2008, quando a Superintendência Regional do Instituto Nacional de Colonização e Reforma Agrária (INCRA) presidida por um aliado do MST foi convidada a participar do COTAE pelo MDA, ela tentou mobilizar os líderes locais do MST, mas eles não estavam mais interessados no espaço de negociação do COTAE, que Ihes parecia demasiado desfavorável e pouco suscetível de atender às suas demandas.
} 
Confederação Nacional dos Trabalhadores da Agricultura (CONTAG). Sua aliança sindical e, sobretudo, seu não alinhamento aos técnicos das EMATER, levaram à sua substituição rápida: primeiro por um técnico de uma ONG de agrônomos favorável às EMATER, mas não alinhado ao PT, e, logo, por um consultor, diretamente contratado pela SDT-MDA.

Mede-se o papel ao mesmo tempo ambíguo, militante e precário (sendo pouco e muito irregularmente pago) do articulador territorial financiado pelas ONGs parceiras da SDT. No entanto esses agentes se beneficiam de uma forma de remuneração profissional da militância como observado por Nonjon (2005) em dispositivos territoriais da França. O articulador, de um lado, é submetido à precariedade do emprego, à falta de reconhecimento e a uma eventual e irregular remuneração militante; e, do outro lado, trabalha no cotidiano com funcionários de carreira, confortavelmente instalados e bem remunerados para realizar a mesma função. Ele tem, portanto, a tentação de compensar essa falta de recursos pela orientação dos projetos ou contratos de estudos no território a favor da ONG que o emprega, do sindicato que o promoveu ou do político que o apadrinha. No caso do TAE, o articulador recuperou o veículo destinado ao apoio à comercialização dos produtos dos agricultores e obrou para que a gestão do centro de capacitação fosse atribuída a sua ONG.

No mesmo plano, mas na escala federal, a relação neocorporativista ${ }^{4}$ entre o MDA e os movimentos sociais da agricultura familiar (a imagem de outros ministérios com outros setores) tem dado lugar a relações clientelistas como no caso do COTAE, mas tem levado, também, a resistências ou a rupturas como aquela operada pelo Movimento dos Trabalhadores Sem Terra (MST) e as organizações da Via Campesina Brasil, ou ainda por agentes de serviços públicos hostis à participação.

Entre os três níveis de governo (Figure 2), as resistências corporativistas mais virulentas provêm raramente dos agentes do Estado federal, confortados pelo seu estatuto privilegiado de alto funcionário. Observaram-se, sobretudo, oposições e boicote da dinâmica territorial quando o governo estadual ou municipal se encontra na oposição à coalizão pró-governamental, o que era o caso no DF e nos dois outros Estados Federados membros do TAE durante nosso estudo. Reações e relações corporativistas ou clientelistas fortes opõem também os sindicatos da agricultura familiar e as ONGs entre eles, em torno de considerações ao mesmo tempo ideológicas e financeiras em matéria de competição para estabelecer e controlar as bases sociais (Jobert, 1983).

\section{Projetos territoriais do COTAE e relações clientelistas}

Apesar da proposta de "gestão social territorial e participativa" do PRONAT (Brasil, 2005), a análise da elaboração, seleção e financiamento dos projetos "coletivos" do TAE mostra diversos disfuncionamentos e tomada de decisões em espaços paralelos ou "ad hoc", fora do quadro do COTAE (Massardier et al., 2012; Egret, 2013).

O conteúdo e as modalidades de financiamento dos projetos territoriais dependiam amplamente de relações diretas entre os funcionários do MDA e os beneficiários através de diversos intermediários ou mediadores: o próprio articulador territorial, os consultores da SDT, as ONG parceiras e, obviamente, os agentes das EMATER (Ávila, 2011). Essas mediações relevam do clientelismo local ou de práticas administrativas neocorporativistas ${ }^{5}$ (Jobert \& Muller, 1987). A partir do momento que o Estado tem proposto aos movimentos sindicais e à sociedade civil (ONG) um novo nível territorial sem capacidade administrativa e, sobretudo, sem regras de funcionamento validadas, esses entraram em competição para representar as

\footnotetext{
${ }^{4}$ Trata-se de uma forma de "neocorporativismo distribuído" (Bobbio et al., 2007) mais de que da gestão social territorial (Oliveira, 2011) ou da cogestão (segundo o modelo francês entre o principal sindicato de agricultores a FNSEA e o Ministério da Agricultura, ver Jobert \& Muller, 1987) porque cada secretariado ou setor do MDA foi concedido a um dos movimentos sociais da agricultura familiar (CONTAG, MST, Cooperativas da Agricultura Familiar, ver Sabourin, 2015).

${ }^{5}$ Segundo Bobbio et al. (2007, p 818), “[...] num sistema neocorporativista a organização representativa de interesses particulares é livre para aceitar ou não suas relações com o Estado, contribuindo, portanto, para defini-las enquanto que no corporativismo clássico é o próprio Estado que impõe e define estas relações".
} 
mesmas bases sociais da agricultura familiar e captar recursos, contribuindo para a reprodução de esquemas clientelistas já existentes ${ }^{6}$.

No TAE, o caso da obtenção do projeto para construir e administrar o Mercado Orgânico na CEASA do DF é exemplar desse tipo de mecanismo. Uma minoria de pequenos empresários produtores orgânicos do DF tem conseguido monopolizar os recursos do PRONAT, teoricamente reservados ao segmento da agricultura familiar, por meio de diversos recursos políticos. O grupo de produtores orgânicos conseguiu o financiamento do mercado e de equipamentos com o apoio de um agrônomo e empresário do setor que foi presidente da EMATER-DF, do Sindicato de produtores Orgânicos, Secretário de Estado de Ciência e Tecnologia do DF e é deputado distrital.

Esse grupo de dez produtores justificou o projeto argumentando que beneficiaria 80 agricultores familiares orgânicos do DF. Conseguiram associar três deles na sua cooperativa e logo colocaram barreiras para a entrada de mais familiares, exigindo uma cota social elevada e a certificação por auditoria externa (Landel, 2009). Um pequeno grupo de empresários da piscicultura do DF, diretamente apadrinhado pelo Ministro da Pesca, obteve ainda mais facilmente o financiamento de um mercado dos peixes e veículos frigoríficos, criando uma associação com 70\% de pescadores artesanais (tendo estatuto de agricultor familiar), mas nenhum deles conseguiu vender sequer um peixe nesse mercado (Egret, 2013).

No DF e nos municípios de Goiás, essa minoria de empresários pluriativos exercendo profissões liberais ou aposentados da função pública compartilhou importantes recursos do PRONAT com os técnicos dos serviços de extensão. Conseguiram instrumentalizar a direção e a assembleia do COTAE por meio da potente rede dos engenheiros agrônomos da região. Tinham, ao mesmo tempo, os meios de influenciar as decisões nos diversos níveis da governança do PRONAT (Figure 2) e a legitimidade ou a competência técnica para orientar o conteúdo dos projetos (Ávila, 2011). Conseguiram por meio dessa rede profissional tecer alianças com outros agrônomos ou técnicos das ONGs, do setor privado e das secretarias municipais de agricultura, e constituir um bloco maioritário no COTAE. Isso foi facilitado pelo absenteísmo das outras categorias: os agricultores familiares por falta de tempo e de recursos e os representantes dos serviços federais ou estaduais não agrícolas, menos motivados (Ávila et al., 2011). Puderam fazer financiar para as suas instituições equipamentos informáticos, veículos e, sobretudo, contratos para estudos ou capacitações a título do apoio à agricultura familiar. Nos três casos indicados acima, a maioria da população alvo do PRONAT, os agricultores familiares e os beneficiários da reforma agrária só conseguiram obter pequenos projetos ou efeitos indiretos dos projetos estruturantes.

No caso do Estado de Minas Gerais, o essencial dos financiamentos do TAE foi captado pelo município de Unaí que mobilizou uma coalizão mais ampla reunindo numa base clientelista local (a troca de postos na prefeitura) os serviços municipais, a EMATER-MG e o sindicato municipal dos Trabalhadores Rurais (STR) da CONTAG. O COTAE, não tendo existência jurídica que permitisse receber ou administrar fundos federais, teve suas infraestruturas e equipamentos coletivos destinados aos agricultores familiares (armazéns, mercado dos produtores, tratores, etc.) adquiridos pela Prefeitura de Unaí, que tem redistribuído o acesso segundo as lógicas clientelistas locais. O prefeito não vacilou em substituir o logo do COTAE por aquele do seu governo municipal colado nos tratores financiados via o TAE pelo MDA e destinados a realizar trabalhos para os agricultores familiares do município.

Finalmente, o aperfeiçoamento da lógica clientelista pelos pequenos empresários e pelos agrônomos dos serviços de extensão consistiu em aproveitar do seu posto de conselheiro territorial para "entrar na política", sendo candidato nas eleições municipais, distritais ou estaduais (Massardier et al., 2012). Um técnico da Agência Rural de Goiás, membro do COTAE, e candidato a deputado na assembleia legislativa fazia campanha durante

\footnotetext{
${ }^{6}$ Em outros lugares no Brasil, as observações são as mesmas: no Estado do Acre, o processo territorial rural foi colocado sob a supervisão de ONGs (Toni, 2007); na região de Marabá, no Pará, a tendência sindical de agricultura familiar apoiada pelo MDA derrubou no CODETER a maioria sindical histórica resultante das lutas pela terra e pela reforma agrária; no território do Portal da Amazônia, Mato Grosso, apesar do fortalecimento dos movimentos de agricultura familiar vinculados à Via Campesina, os jovens líderes permaneceram sob a tutela de ONGs e da Igreja Católica.
} 
as reuniões do colegiado territorial. Muito naturalmente, pedia o voto maciço dos agricultores familiares para obter uma melhoria dos salários e condições de trabalho dos serviços de ATER (Egret, 2013). Questionado sobre o alvo reduzido e corporativista do seu discurso: porque não fundava a sua campanha na melhoria dos serviços para os agricultores familiares (sendo precisamente a missão da sua instituição) que representavam bem mais eleitores que os extensionistas na sua circunscrição, ele assegurava seriamente que, de todo modo, os agricultores votariam para o candidato indicado pela Agência Rural de Goiás. Sua prioridade era realmente obter o aval e apoio dos seus pares e colegas que, por acaso, poderiam também, eles mesmos, se tornar candidatos.

\section{Clientelismo e relações de reciprocidade}

Na parte anterior, a leitura empírica das práticas clientelistas do TAE e dos seus projetos examinou, sobretudo, relações instrumentais e jogos aplicados ao benefício de recursos materiais ou de recursos políticos (cargos ou postos de poder). No entanto, o exame aprofundado de práticas qualificadas de clientelistas pelo prisma da teoria da reciprocidade permite identificar também valores afetivos, sociais e éticos associados a essas relações, configurando um quadro social menos mecânico e mais complexo.

\section{Relações de reciprocidade e dimensão afetiva da clientela}

A associação demasiado rápida entre clientelismo e corrupção pode, de fato, mascarar formas de solidariedade, de resistência (Scott, 1986) e de redistribuição (Polanyi, 1944). São relações de reciprocidade, muitas vezes centralizadas ou até assimétricas, que geram serviços mútuos, mas que produzem, também, sentimentos e valores éticos entre as duas partes.

Muitas práticas de clientelismo observadas no marco do TAE não correspondem a relações de instrumentalização, de exploração ou de troca desigual, mas a prestações de redistribuição associadas à existência de poderes e de estatutos diferenciados. A diferença entre troca desigual e redistribuição (ou reciprocidade centralizada) tem a ver com os valores humanos gerados pelos modos de relacionamento. As obrigações sociais ou econômicas que as lideranças associativas ou sindicais do TAE têm que assegurar em função de regras de reciprocidade fazem parte dessas práticas de redistribuição, muitas vezes qualificadas de clientelistas, quando não de desvio ou de corrupção. É, por exemplo, o caso do uso dos fundos ou das infraestruturas que não correspondem aos esquemas estabelecidos pelos imperativos técnicos ou administrativos dos projetos.

Os dirigentes das organizações de agricultores que recebem ajudas ou equipamentos são submetidos a duas pressões contraditórias: aquela da sua comunidade ou base social que exige a redistribuição e aquela dos serviços técnicos que exigem o investimento produtivo para a acumulação. Para não ser condenado pelos seus, o dirigente camponês deve redistribuir de acordo com as regras comunitárias. Mas, lembra Temple (2003, p. 197), “[...] os agricultores que querem perenizar o seu sistema de reciprocidade, consideram essa redistribuição como um ato justo, que interrompe o ciclo de investimento produtivo de um sistema destrutor do seu sistema de reciprocidade e dos seus valores".

Um dirigente agricultor é muitas vezes objeto dessa dupla crítica: a da sua comunidade e a dos serviços de desenvolvimento do governo. A pressão comunitária conduz a privilegiar as redes de proximidade e as relações de reciprocidade e redistribuição: por exemplo, a fazer beneficiar seus próximos ou vizinhos do acesso aos tratores do projeto, às capacitações do COTAE. Essas práticas são automaticamente interpretadas pelos políticos locais e serviços técnicos em termos de abuso de poder, como se fossem diferentes as ações políticas do Estado ou do município.

Não se trata de justificar esses comportamentos, nem de tomar partido para a lógica de redistribuição e reciprocidade contra aquela da troca, mas de mostrar em que medida elas são de natureza diferente e correspondem a projetos sociais e econômicos também diferenciados. 
Segundo a mesma lógica de redistribuição, às vezes, as comunidades de agricultores familiares do TAE aceitaram projetos produtivos que pareciam incoerentes à primeira vista com seus sistemas de cultivo ou necessidades prioritárias (casa de farinha onde não tem mandioca, garagem onde não há trator ou armazém onde não existe comercialização). Mas, de fato, eram equipamentos solicitados na perspectiva de ampliar o laço social ou de participar de novas relações sociais, isto é, de fortalecer estruturas ou ciclos de reciprocidade. Infraestruturas produtivas (casa de farinha, garagem do trator, armazém para produtos) têm sido solicitadas por assentamentos de reforma agrária nos municípios do TAE, muitas vezes, para dispor de um salão de festas, de uma capela, de um centro de reunião ou até de um local para a escola, quer dizer, para serviços públicos de primeira necessidade, que permitem também o desenvolvimento de relações sociais, espirituais e culturais da comunidade. Os responsáveis associativos indicam que, mesmo se as suas prioridades são de outra natureza, a única modalidade de apoio acessivel no PRONAT, era o financiamento de equipamentos e de infraestruturas coletivas como armazéns e casas de farinha.

Por outra parte, os sentimentos e valores éticos produzidos pelas práticas de reciprocidade numa relação de clientela são identificados pelos protagonistas em termos de afetividade: reconhecimento, amizade, confiança, mas também, respeito e obediência.

A relação proprietário/morador/meeiro ou patrão/assalariado, por exemplo, compreende obrigações mútuas que se prolongam por relações afetivas, podendo, às vezes, conduzir a uma forma de compadrio assimétrico (Sabourin, 2009). No TAE, os beneficiários mais recentes da reforma agrária de Unaí-MG ou de São Sebastião-DF dependem da ajuda dos tratores por meio da Prefeitura e do trabalho assalariado no exterior, na espera de que as suas parcelas ou os seus rebanhos se tornem produtivos. Uma parte desses agricultores preferiu prolongar a relação afetiva de clientela com os seus antigos patrões em lugar de entrar na relação clientelista com o prefeito ou os vereadores para o acesso ao trator. Trabalham pontualmente como diaristas na fazenda do ex-patrão e ele manda arar ou plantar as suas parcelas.

Enfim, num vasto território como o TAE, dividido entre três unidades federadas e 19 municípios, os pertencimentos identitários e locais se superpõem às lógicas de coalizão dos partidos e dos movimentos sociais, gerando fenômenos de inclusão e de exclusão que escapam também às regras da participação política (Massardier et al., 2012). Assim, o Município de Unaí-MG é o único que tem conseguido rivalizar com as redes políticas dos empresários rurais do DF, obtendo do COTAE o financiamento de dez projetos entre 2004 e 2015 (Egret, 2013). A solidariedade e a identidade local, as relações afetivas e de proximidade têm jogado tanto quanto o mecanismo clientelista conduzido pela Prefeitura de Unaí, com a CONTAG e a EMATER-MG. Em tal caso, as dimensões afetivas e éticas são difíceis de dissociar das relações instrumentais.

\section{Perspectivas sobre o clientelismo paternalista no Brasil}

O clientelismo não deixa de ser uma relação de troca política desigual. Portanto, o cruzamento entre clientelismo e participação deve ser também confrontado a outra característica da sociedade brasileira, a opressão paternalista herdada da tradição escravagista (Geffray, 2007). O estudo das políticas de desenvolvimento rural em nível nacional no Brasil evidenciou um mecanismo de dupla alienação vindo da conjunção entre opressão paternalista e exploração capitalista (Sabourin, 2009, 2011). Nesse quadro, ao mesmo tempo clientelista e paternalista, a exploração capitalista resiste à crítica social ou revolucionária; assim, tende a perpetuar um ciclo pernicioso associando essas duas formas de alienação.

Podemos nos interrogar por que, fora as ações do MST, as revoltas no campo têm se tornado tão raras e as recuperações ou tutelas dos movimentos sociais tão frequentes ou fáceis?

Um primeiro elemento de resposta é que se as relações sociais, econômicas e políticas no Brasil funcionassem unicamente segundo as regras da troca capitalista, a crítica marxista já teria motivado revoltas, rupturas ou alternâncias de poder durante o século XX. 
Em segundo lugar, além dos limites da crítica marxista, na ausência de uma crítica da alienação própria da reciprocidade assimétrica (a opressão paternalista), esta continua a se sobrepor às reivindicações no campo. Usa-se para isso sempre de algum pretexto maior para justificar a manutenção da opressão paternalista no Brasil: o pretexto do colonialismo (Faoro, 2001), aquele do progresso republicano (Nunes Leal, 1948), aquele da manutenção da ordem econômica anterior (durante a ditadura militar contra a Ligas Camponesas do Nordeste) ou hoje, aquele da contribuição em divisas do agronegócio exportador contra as leis trabalhistas, de reforma agrária e de regularização fundiária.

Assim, o clientelismo não constituiria, em certos casos, uma forma de autodefesa imune contra o pior a vir, a saber a generalização da troca capitalista e a desumanização pela exclusão social.

Esse "pior" poderia ser, como escreve Temple (2003, p. 374), “[...] a reciprocidade ao serviço da troca que se substituiria a troca ao serviço da reciprocidade". Podemos de fato nos interrogar se as práticas de troca e de acumulação ao serviço da reciprocidade mesmo desigual (o clientelismo) não seriam mais sadias, menos hipócritas e mais humanas, que enfeudar sistematicamente a reciprocidade ao desenvolvimento do capital de maneira perfeitamente consciente.

A crítica deve primeiro evidenciar os efeitos de duas noções e lógicas distintas: o que releva da reciprocidade e o que tem a ver com a desigualdade. Mas convém examinar também a articulação da reciprocidade desigual (o tributo) com a acumulação capitalista, a saber, o modelo do grande domínio fundiário da fazenda.

O sistema de "morada" nas fazendas praticamente despareceu no Brasil, a não ser em algumas fazendas do Nordeste tidas como atrasadas. Mas essa prática tem conseguido também evitar a exclusão social ligada à extensão da troca capitalista. Confesso que tenho demorado mais de vinte anos de trabalho no Brasil para escrever sobre essa realidade. Em 1964, durante a ditatura militar, foi publicado o Estatuto do Trabalhador Rural (concebido para os assalariados agrícolas das grandes fazendas e dos engenhos de cana-de-açúcar) obrigando os proprietários a assinar a carteira de trabalhador aos meeiros e moradores nas suas terras. Os fazendeiros expulsaram boa parte deles porque ou não os queriam ou, em certos casos, não podiam registrá-los e remunerá-los a tempo completo. A maioria desses camponeses moradores perderam de uma vez o acesso à terra, trabalho, alimentação, habitação e proteção. Meu primeiro trabalho no Brasil em 1990, foi na Superintendência de Desenvolvimento do Nordeste, a SUDENE, no Programa de Apoio ao Pequeno Produtor rural (PAPP). Quando fui entrevistar pequenos produtores e perguntei qual era seu maior problema, me indicaram na sua maioria "a SUDENE". Pois, para meu assombro, eles associavam os créditos para pecuária do Banco do Nordeste e da SUDENE aos verdadeiros motivos que explicavam a sua expulsão das terras do patrão, "foi por conta dos projetos da SUDENE" (Sabourin, 2011).

\section{Conclusão}

O modelo de ação pública territorial do PRONAT propõe uma associação complexa entre planejamento participativo e controle vertical do financiamento de projetos de infraestruturas coletivas. A implementação do planejamento territorial ascendente foi pensada para favorecer a emergência e a formalização de novas demandas sociais e de novas alianças entre atores. Essa abordagem deveria ter permitido levar em conta a diversidade regional, ecológica e étnica da agricultura familiar brasileira, o que não foi sempre o caso. A elaboração de projetos coletivos considerava possibilidades de conquista de espaços de negociação entre agricultores familiares, atores e gestores locais e poderes públicos para promover uma ação pública territorial. De fato, vários fatores levaram a manter ou reconfigurar práticas clientelistas e a contrapor a participação.

A existência do novo nível territorial sendo limitado a um colegiado sem personalidade jurídica e as regras de financiamento ou de implantação de infraestruturas de origem federal obrigaram as ações e projetos a dependerem do poder dos governos municipais ou estaduais (Grisa \& Schneider, 2014). Isto significou uma passagem obrigada pelo antigo quadro 
constitucional, já marcado por práticas clientelistas e sem dúvida tem representado um obstáculo à renovação participativa dos processos de implementação das ações territoriais.

Os projetos territoriais oferecem também exemplos de tensões entre democracia técnica participativa e democracia representativa (Callon et al., 2001). Qual é a vantagem, sobretudo a meio e longo prazo, de ter procurado contornar a democracia representativa municipal, quaisquer que sejam os seus limites, opondo-Ihe uma frágil democracia técnica mais ou menos participativa? Quinze anos após a transição do PRONAF "Infraestruturas municipais" ao PRONAT, podemos indagar se não teria sido mais fácil, eficiente e prioritário dotar o MDA de meios para melhorar, avaliar e controlar os projetos na escala municipal. Para superar os limites da escala municipal, melhorando ao mesmo tempo a democracia local, a opção poderia ter sido de democratizar e desenvolver os consórcios intermunicipais de desenvolvimento. Essa forma de estrutura intermunicipal já reconhecida pela constituição federal está dotada de um estatuto jurídico que lhe permite administrar fundos e dotações federais (Sabourin et al., 2011).

A permanência, as mutações e adaptações do clientelismo político no Brasil têm a ver com o fato de esse país associar ao mesmo tempo relações estruturantes de troca mercantil capitalista e relações estruturantes de reciprocidade, mesmo sendo assimétricas e desiguais. Cumula, portanto, duas formas de alienação respectivas aos dois sistemas: a exploração capitalista para a acumulação privada de um lado, e do outro, a opressão paternalista, por meio da dominação dos grandes domínios rurais, empresariais ou capitalistas. Ora, a crítica humanista a partir das regras da democracia ou dos direitos dos homens é inoperante (como o foi a crítica revolucionária marxista) diante dessa dupla alienação. A análise crítica específica desse sistema misto associando reciprocidade assimétrica e troca desigual deve ainda ser desenvolvida como o mostrou a grande dificuldade dos partidos progressistas de esquerda e do Partido dos Trabalhadores, uma vez no poder, a fazer política de uma maneira diferente.

\section{Referências}

Avelino Filho, G. (1994). Clientelismo e política no Brasil: revisitando velhos problemas. Novos Estudos CEBRAP, $38,225-240$.

Ávila, M. (2011). Ação pública territorializada de desenvolvimento rural: o caso do Território Águas Emendadas (Tese de doutorado). Universidade de Brasília, Brasília.

Ávila, M., Sabourin, E., Duarte, L., \& Massardier, G. (2011). ATER e desenvolvimento territorial: uma análise crítica. Journal of Extension and Rural Studies, 1(2), 427-448.

Avritzer, L. (2008). Sociedade Civil, Instituições Participativas e Representação: da Autorização à Legitimidade da Ação. Dados, 50(3), 443-464.

Avritzer, L. (Org.). (2009). Experiências nacionais de participação social. São Paulo: Cortez.

Bobbio, N., Mateucci, N., \& Pasquino, G. (2007). Dicionário de política. Brasília: UnB.

Brasil. (1988). Constituição da República Federativa do Brasil de 1988. Recuperado em 25 de março de 2018, de http://www.planalto.gov.br/ccivil_03/constituicao/constituicao.htm

Brasil. Ministério do Desenvolvimento Agrário - MDA. (2005). Referências para uma Estratégia de Desenvolvimento Rural Sustentável. Brasília: MDA-SDT.

Brasil. Controladoria Geral da União. Controle Social. (2008). Orientações aos cidadãos para participação na gestão pública e exercício do controle social. Brasília: Controladoria Geral da União. Recuperado em 12 de agosto de 2019, de www.gespublica.gov.br/folder_rnpg/folder_nucleo/RJ/pasta.2013-0520.02006812602/09.ParticipacaoeControleSocial-conceitoseorientacoes.pdf

Briquet, J. L. (1998). La politique clientélaire. Clientélisme et processus politiques In J. L. Briquet \& F. Sawicki. Le clientélisme politique dans les sociétés contemporaines (pp 7-38). Paris: PUF.

Bursztyn, M. (2008). O poder dos donos. Planejamento e Clientelismo no Nordeste (3. ed.). Rio de Janeiro: Vozes.

Callon, M., Lascoumes, P., \& Barthe, Y. (2001). Agir dans un monde incertain. Essai sur la démocratie technique. Paris: Le Seuil.

Carvalho, J. M. (1997). Mandonismo, coronelismo, clientelismo: uma discussão conceitual. Dados, 40(2). Recuperado em 1 de outubro de 2018, de http://www.scielo.br/scielo.php?script=sci_arttext\&pid=S0011$52581997000200003 \&$ Ing=en\&nrm=iso 
Carvalho, J. M. (2003). A construção da ordem: a elite política imperial. Teatro das Sombras: a política imperial. Rio de Janeiro: Civilização Brasileira.

Centro Estratégico Latino-Americano de Geopolítica - CELAG. (2017). Evangelical churches and conservative power in Latin America. Recuperado em 8 de novembro de 2017, de http://www.celag.org/iglesiasevangelicas-poder-conservador-latinoamerica

Dagnino, E. (Org.). (1994). Anos 90: política e sociedade no Brasil. São Paulo: Brasiliense.

Dagnino, E., \& Tatagiba, L. (2010). Mouvements sociaux et participation institutionnelle, répertoires d'action collective et dynamiques culturelles dans la difficile construction de la démocratie brésilienne. Revue Internationale de Politique Comparée, 17(3), 167-186.

Egret, L. (2013). Trajectoire de projets et stratégies d'acteurs dans le Territoire Aguas Emendadas (Brésil) (Tese de maestría). Université de Montpellier III, Montpellier.

Elias, N. (1994). A sociedade dos indivíduos. Rio de Janeiro: Zahar.

Faoro, R. (2001). Os donos do poder: formação do patronato político brasileiro (3. ed.). São Paulo: Globo.

Farias, F. P. (2000). Clientelismo e democracia capitalista: elementos para uma abordagem alternativa. Revista de Sociologia e Politica, 15, 49-65.

Freitas, A. F. (2016). Por uma abordagem relacional do desenvolvimento territorial rural. Revista de Economia e Sociologia Rural, 54(4), 667-690. Recuperado em 6 de outubro de 2018, de http://www.scielo.br/scielo.php?script=sci_arttext\&pid=S0103-20032016000400667\&lng=en\&nrm=iso

Garcia Junior, A. (1990). O Sul. caminho do roçado. Brasília: Marco Zero/UnB/CNPq-MCT.

Geffray, C. (2007). A opressão paternalista: cordialidade e brutalidade no cotidiano brasileiro. Rio de Janeiro: Educam-Editora universitária Candido Mendes.

Gohn, M. G. (2011). Conselhos gestores e participação sociopolítica (4. ed.). São Paulo: Cortez.

Goirand, C. (1998). Clientélisme et politisation populaire à Rio de Janeiro. In J. L. Briquet \& F. Sawicki. Le clientélisme politique dans les sociétés contemporaines (pp. 111-143). Paris: PUF.

Grisa, C., \& Schneider, S. (2014). Três gerações de políticas públicas para a agricultura familiar e formas de interação entre sociedade e estado no Brasil. Revista de Economia e Sociologia Rural, 52(Supl. 1), 125-146.

Grisa, C., Wesz Junior, V. J., \& Duarte, V. B. (2014). Revisitando o Pronaf: velhos questionamentos, novas interpretações. Revista de Economia e Sociologia Rural, 52(2), 323-346.

Grossman, E., \& Saurugger, S. (2006). Les groupes d'intérêt au secours de la démocratie? Revue Française de Science Politique, 56(2), 299-321. http://dx.doi.org/10.3917/rfsp.562.0299

Instituto de Pesquisa e Economia Aplicada - IPEA. (2012). Desenvolvimento rural. In Instituto de Pesquisa e Economia Aplicada - IPEA. Políticas sociais: acompanhamento e análise ( $\left.\mathrm{N}^{\circ} 20\right)$. Brasília: IPEA.

Jesus Junior, G., \& Costa Cosenza, L. Z. (2015). A importância da participação popular através dos Conselhos Municipais na formulação e aplicação de políticas públicas no âmbito local. Jus.com.br. Recuperado em 1 de outubro de 2019, de https://jus.com.br/artigos/44883/a-importancia-da-participacao-popularatraves-dos-conselhos-municipais-na-formulacao-e-aplicacao-de-politicas-publicas-no-ambito-local

Jobert, B. (1983). Clientélisme, patronage et participation populaire. Revue Tiers Monde, 24(95), 535-556.

Jobert, B., \& Muller, P. (1987). L'État en action: politiques publiques et corporatisme. Paris: PUF.

Landel, P. (2009). Sociogenèse d'un projet de développement rural territorialisé: le cas du Marché Organique de Brasilia, Territoire Aguas Emendadas (Mémoire de master). Université Lyon II, Lyon.

Lanna, M. P. D. (1995). A dívida divina. Troca e Patronagem no Nordeste Brasileiro. Campinas: Ed. Unicamp.

Lecuyer, L. (2009). Les représentants de l'agriculture familiale dans la politique participative territoriale brésilienne: de nouveaux leaders de l'action publique évoluant dans un système politique hybride (Mémoire de master). Université Paris 1 Panthéon Sorbonne, Paris.

Leite, S. P., \& Wesz Junior, V. J. (2012). Um estudo sobre o financiamento da política de desenvolvimento territorial no meio rural brasileiro. Revista de Economia e Sociologia Rural, 50(4), 645-666. http://dx.doi.org/10.1590/S0103-20032012000400004

Martins, J. S. (1994). O poder do atraso: ensaios de sociologia da história lenta (174 p.). São Paulo: Editora Hucitec.

Massardier, G. (2008). Politiques et actions publiques. Paris: Armand Colin. 
Massardier, G., Sabourin, E., Lecuyer, L., \& Ávila, M. L. (2012). La démocratie participative comme structure d'opportunité et de renforcement de la notabilité sectorielle. Le cas du Programme de Développement Durable des Territoires Ruraux au Brésil, Territoire Aguas Emendadas. Participations, 1(2), 78-102.

Mauss, M. (1931). Fuvres (Vol. 3, pp. 1968-1969). Paris: Ed. de Minuit.

Medard, J. F. (1976). Le rapport de clientèle: du phénomène social à l'analyse politique. Revue Française de Science Politique, 26(1), 103-131.

Nonjon, M. (2005). Professionnels de la participation. Savoir gérer son image militante. Politix, 2, 89-112.

Nunes Leal, V. (1948). Coronelismo, enxada e voto. O Município e o regime representativo no Brasil. Rio de Janeiro: Revista Forense.

Oliveira, J. H. (2011). Programa territórios da cidadania: multiplicar a ideia, focar as ações. Simão Dias: Brochura.

Pellegrini Filho, A., \& Rovere, M. (2011). Participação social na definição e implantação de políticas públicas. Rio de Janeiro: Portal DSS Brasil. Recuperado em 1 de agosto de 2011, de http://cmdss2011.org/site/2011/08/participacao-social-na-definicao-e-implantacao-de-politicas-publicas/

Perafan, V. M. E., Sabourin, E., Sayago, D., \& Balestro, M. (2018). O programa de desenvolvimento sustentável de territórios rurais. In E. Sabourin \& C. Grisa (Orgs.), A difusão de políticas brasileira para agricultura familiar na América Latina e Caribe (pp. 89-114). Porto Alegre. Ed. Escritos.

Polanyi, K. (1944). The great transformation: the political and economic origins of our time. Boston: Beacon Press.

Porto de Oliveira, O. (2017). International policy diffusion and participatory budgeting - ambassadors of participation, international institutions and transnational networks (269 p.). London: Palgrave Macmillan

Sabourin, E. (2009). Camponeses do Brasil, entre troca e reciprocidade. Rio de Janeiro: Garamond U.

Sabourin, E. (2011). Organizações e sociedades camponesas: uma leitura atraves da reciprocidade (240p.). Porto Alegre: Ed. da UFRGS.

Sabourin, E. (2015). Evolução da política federal de desenvolvimento territorial no Brasil. Novos Cadernos NAEA, 18(1), 123-143. http://dx.doi.org/10.5801/S21797536

Sabourin, E., Caldas, E., \& Moreira, I. (2011). Politiques de développement territorial et intercommunalité au Brésil: tensions et complémentarités. Revue d'Economie Méridionale, 59(233-234), 7-32.

Sabourin, E., Tonneau, J. P., \& Caron, P. (1997). Seu Néné, leader paysan à Massaroca (Bahia, Brésil): une trajectoire Nordestine. Le Bulletin de l'APAD, 102-107.

Sayago, D. A. V. (2000). A invenção burocrática da participação: discursos e práticas no Ceará (Tese de doutorado). Centro de Desenvolvimento Sustentável, Universidade de Brasília, Brasília.

Schneider, S., Silva, M. K., \& Moruzzi, M. P. (2003). Políticas Públicas e Participação Social no Brasil Rural. Porto Alegre: Ed UFRGS.

Scott, J. C. (1986). Everyday forms of peasant resistance. The Journal of Peasant Studies, 13, 2.

Scubla, L. (1985). Logiques de la réciprocité (No. 6). Paris: Ecole Polytechnique, Cahiers du CREA.

Temple, D. (1998). Les structures élémentaires de la réciprocité. La Revue du MAUSS, 12(2), 234-242.

Temple, D. (2003). Teoría de la reciprocidad. La Paz: PADEP/GTZ.

Toni, F. (2007). Party Politics, Social Movements and Local Democracy: Institutional Choices in the Brazilian Amazon (WP Series, $n^{\circ} 32$ ). Washington: World Resource Institute.

Wanderley, M. N. B. (2014). Que territórios, que agricultores, que ruralidades? In J. S. Cavalcante, M. N. B. Wanderleey \& P. A. Niederle (Orgs.), Participação, território, cidadania: um olhar sobre a política de desenvolvimento territorial no Brasil (pp 337-351). Recife: Editora UFPE.

Yazbek, C. M. (1993). Classes subalternas e assistência social. São Paulo: Cortez. 